\title{
Alisamento capilar como temática para o ensino de proteína: Uma proposta utilizando a aprendizagem baseada em casos
}

\author{
Hair straightening as a theme for protein teaching: A proposal using case-based learning \\ Alisado del cabello como tema de enseñanza proteínas: Una propuesta que utiliza el aprendizaje
}

basado en casos

Recebido: 14/03/2021 | Revisado: 20/03/2021 | Aceito: 24/03/2021 | Publicado: 01/04/2021

Lorena Garces Silva

ORCID: https://orcid.org/0000-0001-5846-0091 Universidade Federal do Pampa, Brasil E-mail: garceslorenasilva@gmail.com

Camila Aparecida Tolentino Cicuto

ORCID: https://orcid.org/0000-0002-9817-7933 Universidade Federal do Pampa, Brasil E-mail: camilacicuto@unipampa.edu.br Jéssie Haigert Sudati

ORCID: https://orcid.org/0000-0001-9996-0682 Universidade Federal do Pampa, Brasil E-mail: jessiesudati@unipampa.edu.br

\begin{abstract}
Resumo
Este trabalho teve como objetivo propor e aplicar um estudo de caso por meio da temática "alisamento capilar". Para isso, utilizou-se a Aprendizagem Baseada em Casos (ABC) associada ao conteúdo programático de uma disciplina de Fundamentos do Metabolismo oferecida para acadêmicos do $5^{\circ}$ semestre de um curso de Licenciatura. Como instrumento de coleta de dados utilizou-se um questionário em que os estudantes deveriam escolher as alternativas corretas e justificar suas respostas para solucionar o caso proposto. A análise dos dados contemplou uma abordagem qualitativa, a partir da categorização das respostas apresentadas no instrumento. Os resultados deste trabalho evidenciam que os alunos apresentaram dificuldade na resolução da atividade. Este achado pode ser decorrente da falta de experiência dos estudantes em desenvolverem atividades com esta abordagem, ou ainda por não terem compreendido que poderiam assinalar várias alternativas para a resolução do caso. Espera-se com essa pesquisa contribuir com os estudos sobre ABC, bem como auxiliar na compreensão dos conceitos Bioquímicos abordados neste estudo.
\end{abstract}

Palavras-chave: Ensino de bioquímica; Cabelo; Estudo de caso.

\begin{abstract}
This work aimed to propose and apply a case study through the theme "hair straightening". For this, we used a CaseBased Learning (CBL) approach associated with the syllabus of a Metabolism Fundamentals course offered to students of the 5th semester of a teacher training degree course. As a data collection instrument, a questionnaire was used in which students should choose the correct alternatives and justify their answers to solve the proposed case. Data analysis included a qualitative approach, based on the categorization of the answers presented in the instrument. The results of this work show that the students had difficulty in solving the activity. This finding may be due to students' lack of experience in developing activities with this approach, or because they did not understand that they could point out several alternatives to solve the case. This research is expected to contribute to the study about CBL, and it also assists in the Biochemical concepts understanding, investigate in this study.
\end{abstract}

Keywords: Biochemistry education; Hair; Case study.

\section{Resumen}

Este trabajo tuvo como objetivo proponer y aplicar un caso de estudio a través del tema "Alisado del cabello". Para ello, utilizamos el aprendizaje basado en casos (ABC) asociado al plan de estudios de una disciplina de Fundamentos del Metabolismo ofrecido a académicos en el quinto semestre de un curso de grado. Como instrumento de recolección de datos se utilizó un cuestionario en el que los estudiantes deben elegir las alternativas correctas y justificar sus respuestas para resolver el caso propuesto. El análisis de datos incluyó un enfoque cualitativo, basado en la categorización de las respuestas presentadas en el instrumento. Los resultados de este trabajo muestran que los estudiantes tuvieron dificultades para resolver la actividad. Este hallazgo puede deberse a la falta de experiencia de los estudiantes en el desarrollo de actividades con este enfoque, o incluso porque no entendieron que podían señalar 
varias alternativas para resolver el caso. Se espera que esta investigación contribuya a los estudios sobre ABC, además de ayudar a comprender los conceptos bioquímicos cubiertos en este estudio.

Palabras clave: Enseñanza de bioquímica; Cabello; Caso de estúdio.

\section{Introdução}

Situada na interface entre a Química e a Biologia, a Bioquímica é a área interdisciplinar do conhecimento que possibilita relacionar as estruturas e interações moleculares no estudo do funcionamento de organismos vivos (Silva et al., 2017). Um dos fundamentos da Bioquímica é o entendimento das biomoléculas, e dentre elas estão as proteínas (encontradas em maior abundância nos seres vivos). Essas moléculas possuem uma grande variedade estrutural e funcional e estão relacionadas à catálise de reações bioquímicas, ao transporte, à estrutura de tecidos, ao sistema imune e à regulação hormonal (Motta, 2003; Nelson \& Cox, 2014; Campbell, 2000). Com as várias aplicações desta ciência da vida, o seu entendimento tem diversas implicações não só para o avanço da Ciência, mas como também em nossa vida cotidiana. A Bioquímica está presente no desenvolvimento de novos medicamentos, em tratamentos médicos e ainda em tratamentos estéticos, além de muitas outras aplicações que refletem na saúde e qualidade de vida das pessoas (Tibell \& Rundgren, 2010).

O alisamento capilar é um exemplo que se enquadra dentro destas características. A compreensão de tal temática envolve os conceitos de proteína, aminoácidos, ligações químicas (pontes dissulfeto, ligações de Hidrogênio, ligação iônica e ligações peptídicas) e oxidação/redução, além do entendimento da ação de compostos presentes nos alisantes como formol, formaldeído, glutaraldeído, entre outros. Assim, compreender tais conceitos e processos de alisamento capilar é de fundamental importância, pois de acordo com a ANVISA (Agência Nacional de Vigilância Sanitária) o alisamento é classificado como grau de risco 2 sujeitos a registro, ou seja, apresenta substâncias que podem apresentar perigos à saúde. Neste mesmo documento, no Anexo VI consta que os neutralizantes, produtos para ondular e alisar os cabelos não podem ser aplicados se o couro cabeludo estiver irritado ou lesionado e ainda há recomendações para que se mantenha fora do alcance das crianças (Anvisa, 2015). Apesar disso, a maioria os consumidores não conhecem os constituintes químicos destes produtos e a sua forma de utilização adequada. Tais compostos podem ocasionar irritação e até queimadura na pele, ferimentos nas vias respiratórias e danos irreversíveis aos olhos e aos cabelos. Além disso, existem produtos químicos que não podem ser usados em conjunto, pois causam severos danos aos cabelos.

O alisamento capilar começou provavelmente durante a escravidão, com a utilização de materiais gordurosos para o alinhamento dos fios. Foi em meados de 1900 que Sarah Breedlove uma mulher afro-americana (mais tarde conhecida como Madame CJ Walker), elaborou uma pomada para utilizar nos cabelos com a finalidade de alisá-los. O método ficou conhecido como "pressão de calor" ou "pente quente", pois além da pomada era utilizado um pente de metal com temperaturas que variavam de 150 a $250^{\circ} \mathrm{C}$ para a modelagem e alinhamento dos fios (Dias et al, 2007; Syed, 1977). Atualmente são muito utilizadas duas categorias de alisamentos: o temporário e o permanente. Em ambos ocorrem alterações nas ligações químicas do fio de cabelo. No caso do alisamento temporário essas alterações são ocasionadas por agentes como água e calor. Já no caso do alisamento permanente são utilizados alisantes com pH bastante altos ( $\mathrm{pH}>9,0)$, além de utensílios que permite modificar a forma do cabelo. Esta segunda opção é bem mais agressiva, podendo danificar o cabelo e couro cabeludo (Ferreira \& Braga, 2016; Cruz et al., 2016). Neste contexto, o alisamento capilar é uma temática que possibilita abordar os conceitos científicos, tradicionalmente estudados de forma isolada nas aulas de Química e Biologia, aliando questões do cotidiano e que ainda refletem na saúde das pessoas.

Nesta perspectiva algumas perguntas emergem: Que possibilidades de aprendizagem a temática do alisamento capilar possui? Como explorar esta temática nas aulas de Bioquímica? 


\subsection{Aprendizagem Baseada em Casos como estratégia para promoção da aprendizagem ativa}

$\mathrm{Na}$ tentativa de responder os questionamentos apresentados anteriormente, utilizou-se neste trabalho uma abordagem de ensino baseada na Aprendizagem Baseada em Casos (ABC) sobre alisamento capilar associada ao conteúdo programático da disciplina de Fundamentos do Metabolismo, ofertada em um curso de formação de professores.

Uma das primeiras, ou até a primeira instituição a utilizar em seu currículo estudos de caso foi a Harvard Business School (HBS). A utilização da ABC como metodologia de ensino, na referida instituição, teve início em 1920 e hoje é amplamente adotada em diversas universidades pelo mundo (Thistlethwaite et al., 2012). Tal abordagem metodológica ganhou grande notoriedade por permitir que os estudantes trabalhem na resolução de problema, mas também por possibilitar que eles (as) desenvolvam uma postura crítica e ativa na construção do conhecimento (Bittencourt \& Struchiner, 2015).

A $\mathrm{ABC}$ é uma metodologia de ensino que pressupõem a aprendizagem ativa dos alunos, através da resolução de problemas de alta ordem cognitiva HOCS, do inglês High Order Cognitive Skills e processos de pensamento mais elaborados (Zoller, 1993). Os casos propostos devem apresentar situações que possivelmente os alunos precisarão enfrentar no futuro. Assim, os eles (elas) estarão mais bem preparados para lidarem com os desafios da vida cotidiana e/ou profissional. Para isso, os casos propostos devem possibilitar o desenvolvimento de habilidade através de estímulos ao pensamento crítico para a identificação das limitações e potencialidades da solução proposta (Metzner, 2014).

Nas metodologias de ensino que favorecem a aprendizagem ativa (Welter, Foletto \& Bortoluzzi, 2020; Nascimento \& Feitosa, 2020), como no caso da ABC, o professor tem o papel de mediar o processo de resolução dos casos, sem oferecer respostas prontas. Nesta perspectiva, o professor assume o papel de mediador do processo, não cabendo apenas a função de transmitir informações. Sobre o papel dos professores nestes ambientes de aprendizagem Moran (2017, p. 85) argumenta que [...] "quanto mais informação disponível, tanto mais precisamos de quem ajude a escolher, avaliar, interpretar e criar novas sínteses e possibilidades. Precisamos de professores abertos, evoluídos, que ajudem a ampliar os horizontes e a apoiar a evolução dos seus estudantes". Assim, nestes ambientes de aprendizagem os alunos assumem o protagonismo do processo e precisam adotar uma postura ativa para a resolução do caso proposto.

O ensino que pressupõe a participação ativa do aluno no processo de aprendizagem, é o ensino que oportuniza atividades para que os alunos falem, argumentem, proponham soluções, debatam e ainda construam o conhecimento de forma mais autônoma e participativa (Moreira, 2011). Para isso, espera-se que o professor fale pouco e abandone a narrativa (Moreira, 2011). Segundo Moreira (2011, p.6) o problema da narrativa deve-se "a uma avaliação behaviorista, comportamentalista, que permeia a escola. O behaviorismo como referencial para organizar o ensino, amplamente dominante na época da tecnologia educacional, foi abandonado, pelo menos no discurso, em favor do construtivismo".

Assim, aliar o Ensino de Bioquímica utilizando como abordagem metodológica a $\mathrm{ABC}$ nos permite pensar no potencial da temática do alisamento capilar para o ensino desta Ciência fundamentada em uma perspectiva que se opõem ao pensamento neutro, linear, cartesiano e positivista, e ainda baseado na memorização, fragmentação e simples reprodução dos conteúdos.

O objetivo deste trabalho foi propor e aplicar um estudo de caso por meio da temática "alisamento capilar" com estudantes de um curso de Licenciatura.

\section{Metodologia}

Esta pesquisa está vinculada ao trabalho de conclusão do curso em Ciências da Natureza- Licenciatura da primeira autora (Silva, 2018) pela Universidade Federal do Pampa, campus Dom Pedrito.

O presente estudo tem natureza qualitativa do tipo, intervenção pedagógica. Para Damiani et al. (2013, p. 58), as pesquisas desta natureza "são investigações que envolvem o planejamento e a implementação de interferências (mudanças, 
inovações) - destinadas a produzir avanços, melhorias, nos processos de aprendizagem dos sujeitos que delas participam - e a posterior avaliação dos efeitos dessas interferências".

\subsection{Sujeitos da Pesquisa}

Os sujeitos desta pesquisa $(\mathrm{n}=27)$ foram alunos da disciplina de Fundamentos do Metabolismo em uma turma do $5^{\circ}$ semestre de um curso de Licenciatura de uma universidade no estado do Rio Grande do Sul. Um Termo de Consentimento Livre e Esclarecido foi assinado pelos alunos que aceitarem participar desta investigação, assegurando-se o anonimato dos dados de pesquisa e a possibilidade de desistência a qualquer tempo.

\subsection{Estudo de Caso}

Foi elaborada uma proposta didática com uso do tema "alisamento capilar", considerando os seguintes conceitos de Bioquímica: proteínas, aminoácidos, ligações químicas (pontes dissulfeto, ligações de Hidrogênio, ligação iônica e ligações peptídicas) e oxidação/redução. No Quadro 1 foram apresentadas as atividades desenvolvidas considerando dois eixos: 1 Conhecimentos Bioquímicos de proteínas; e 2- Relação entre alisamentos capilares e a Química. As atividades desenvolvidas totalizaram 4 horas e envolveram diferentes estratégias de ensino, tais como: vídeo, aula expositiva dialogada, análise de registros fotográficos sobre o processo de alisamento e estudo de caso.

Quadro 1- Descrição das atividades desenvolvidas.

\begin{tabular}{|l|l|l|}
\hline Eixos & Descrição das atividades & Duração \\
\hline 1-Conhecimentos Bioquímicos & - Apresentação do vídeo sobre estrutura do cabelo: & $2,5 \mathrm{~h}$ \\
de proteínas & https://www.youtube.com/watch?v=7WhRJV_bAiE & \\
& - Discussão sobre o vídeo & \\
& $\begin{array}{l}\text { - Aprofundamento dos conceitos de estrutura capilar (cutícula, córtex e } \\
\text { medula); estrutura química da queratina (ligações químicas e aminoácidos) e } \\
\text { alisamentos (pontes dissulfeto, ligações de H, ligações iônicas, oxidação e } \\
\text { redução). }\end{array}$ & \\
\hline 2-Relação entre alisamentos & - Análise de registros fotográficos sobre o processo de alisamento. & $0,5 \mathrm{~h}$ \\
capilares e a Bioquímica & - Aplicação do Estudo de caso & $1 \mathrm{~h}$ \\
\hline
\end{tabular}

Fonte: Autores.

No primeiro eixo os alunos assistiram ao vídeo "Viagem ao mundo dos átomos". Depois foi realizada uma discussão para identificar as impressões deles sobre a estrutura da matéria a partir do cabelo humano. Também foram aprofundados os conceitos da estrutura capilar, estrutura química da queratina e os alisamentos.

Já no segundo eixo, para uma melhor compreensão do método de alisamento, foi feito e fotografado previamente o procedimento com um produto a base de tioglicolato (o tioglicolato de amônio é um sal de amônio do ácido tioglicólico, que é um bom agente redutor agindo sobre o tiol R-SH). O procedimento para alisamento com esse produto, implica em aplicar no cabelo um creme alisante contendo o ácido tioglicólico que é o agente redutor que quebrará as pontes dissulfeto, separando as cadeias de aminoácidos que formam a queratina, após aplica-se um agente oxidante para fixar as pontes dissulfeto.

As imagens a seguir (Figura 1) ilustram as etapas do alisamento com tioglicolato. O passo 1 é umedecer o cabelo (Figura 1a) e o passo 2 é aplicar o creme alisante (tioglicolato) (Figura 1b). No passo 3 deve-se passar um pente de plástico e 
aguardar 20 min (Figura 1c) e no 4 retirar o creme alisante com água morna (Figura 1d). O passo 5 é enxugar cuidadosamente o cabelo (Figura 1e) e o passo 6 aplicar a loção neutralizante e aguardar 10 minutos (Figura 1f). Passo 7 e 8 Retirar a loção neutralizante (Figura 1g) e aguardar a secagem do cabelo naturalmente (Figura 1h).

Figura 1 - (a) Alisamento com tioglicolato; (b) Umedecer o cabelo; (c) Passar o pente de plástico; (d) Retirar o creme alisante; (e) enxugar cuidadosamente o cabelo; (f) aplicar a loção neutralizante; (g) Retirar a loção neutralizante; (h) aguardar a secagem naturalmente.

(a)

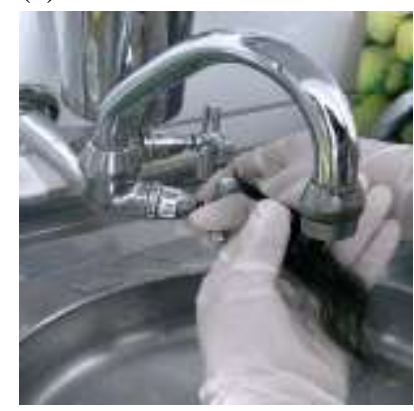

(d)

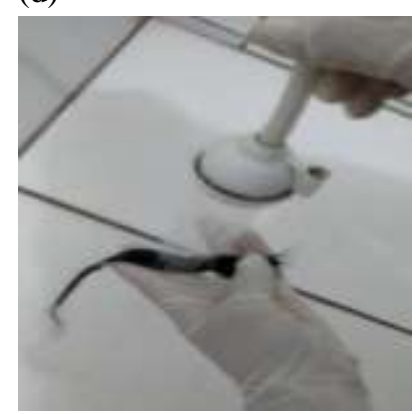

$(\mathrm{g})$

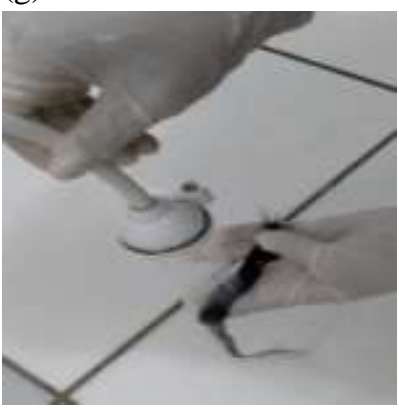

(b)

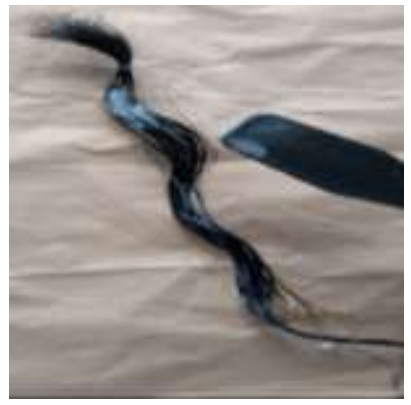

(e)

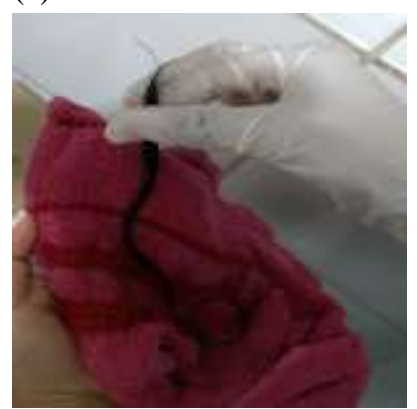

(h)

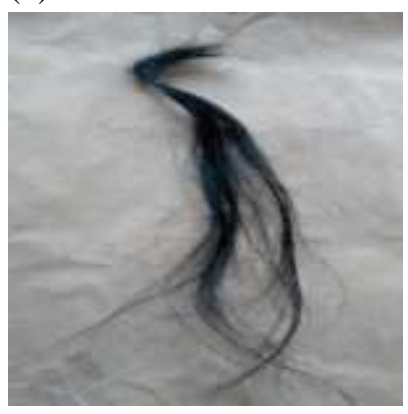

Fonte: Autores. (c)

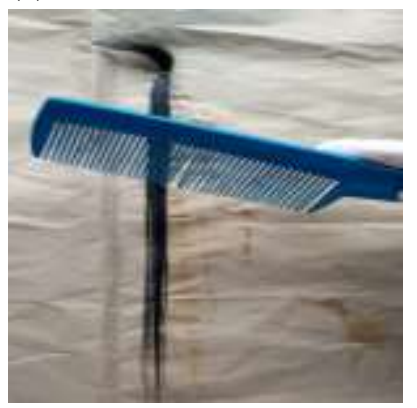

(f)

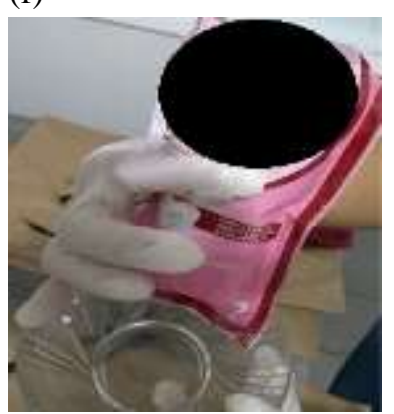

O estudo de caso (Quadro 2) foi elaborado com base nos conhecimentos empíricos e científicos dos acadêmicos e dos conceitos que foram abordados na intervenção didática, com a finalidade de verificar se os mesmos seriam capazes de aplicar os conceitos sobre alisamento capilar e solucionar o caso. 
Quadro 2 - Estudo de caso sobre alisamento capilar.

\section{Maqui vai ao salão de beleza}

A jovem Maqui acordou feliz, hoje ela iria ao salão de beleza tratar de suas madeixas! Maqui assim como muitas mulheres independentes e decididas, adora tratar dos cabelos e experimentar procedimentos capilares diferentes. Seus cabelos, originalmente castanhos escuros, já foram louro mel, rosa e até verdes, embora o verde tenha sido acidental, resultado de uma reação química que ocorreu durante o verão devido a muitos mergulhos na piscina. Atualmente, Maqui está com as pontas de seu cabelo num tom louro acinzentado. Porém devido a tantas descolorações seus cabelos estão um pouco ralos e quebradiços além de estar voltando a forma original, um ondulado tipo 2B (levemente cacheado). Além da coloração, Maqui costuma fazer escovas progressivas, ela já fez: alisamento com formol, com tioglicolatos de amônio, hidróxido de guanidina e carbocisteína. O último alisamento que Maqui fez foi há 6 meses com tioglicolato.

\section{Agora pense:}

Você é o profissional da beleza que vai atender a Maqui! Ela chega a seu salão e pede para que você uniformize o tom acinzentado e acabe com os cachos e o frizz. Ela quer outro alisamento, preferencialmente o alisamento que é a base de $\mathrm{NaOH}$, pois Maqui ouviu falar que este é muito potente!

O que você diria a Maqui? É possível fazer algo pelo cabelo dela?

Lembre-se: Maqui é muito inteligente e não irá se conformar com qualquer resposta. Escolha a (s) alternativa (s) que contempla (m) uma solução e justifique utilizando os conceitos Químicos que achar necessários!

Fonte: Autores (2021).

\subsection{Coleta de Dados}

Como instrumento de coleta de dados foi utilizado um questionário em que os estudantes deveriam escolher as alternativas corretas e justificar suas respostas. No Quadro 3 estão descritas as alternativas correspondentes ao estudo de caso e o aspecto abordado em cada uma delas.

Quadro 3 - Soluções para o estudo de caso.

\begin{tabular}{|l|l|}
\hline Conceito abordado & Alternativa \\
\hline Estrutura capilar & $\begin{array}{l}\text { (A) Fazer uma reconstrução a base de queratina e aminoácidos, para } \\
\text { repor a estrutura do cabelo. } \\
\text { (E) Uniformizar o cabelo de Maqui com tonalizante e aconselhá-la a } \\
\text { não fazer mais alisamentos por um tempo. Indicar produtos que } \\
\text { minimizem o frizz, e hidratações tanto compradas quanto caseiras. }\end{array}$ \\
\hline Compatibilidade química & $\begin{array}{l}\text { B) Se Maqui fez alisamento a base de tioglicolato não poderá fazer } \\
\text { outro a base de NaOH. }\end{array}$ \\
\hline Estrutura capilar e compatibilidade química & $\begin{array}{l}\text { (C) É possível descolorir o cabelo que cresceu, e fazer alisamento a } \\
\text { base de NaOH. } \\
\text { (D) É possível uniformizar o cabelo de Maqui utilizando um tonalizante } \\
\text { sem amônia, deixando o cabelo descolorido próximo a cor original, } \\
\text { então poderá fazer um alisamento a base de tioglicolato, porém o mais } \\
\text { fraco que o mercado oferecer }\end{array}$ \\
\hline
\end{tabular}

Fonte: Autores. 
Com a finalidade de consulta, a tabela de compatibilidade química estava projetada na lousa enquanto os estudantes resolviam o caso. A solução completa para o caso previa que os alunos assinalassem as alternativas A, B e E respectivamente, além de apresentarem a justificativa correta.

\subsection{Análise dos Dados}

As respostas dos alunos no estudo de caso foram categorizadas através da análise de conteúdo (Bardin, 1977). Foram utilizadas três categorias de análise conforme segue:

- resposta satisfatória (RS) - Solucionou completamente marcando todas as alternativas corretas (A, B e E) e justificou;

- resposta parcial (RP)- Solucionou parcialmente marcando uma ou duas alternativas corretas, acompanhada ou não de justificativa;

- resposta insatisfatória (RI) - Marcou alternativas erradas (não solucionou o caso).

\section{Resultados e Discussão}

Na Figura 2 foram apresentados os resultados obtidos a partir da categorização das respostas dos alunos na solução do estudo de caso.

Figura 2 - Resultados das categorias obtidas no estudo de caso.

Estudo de caso

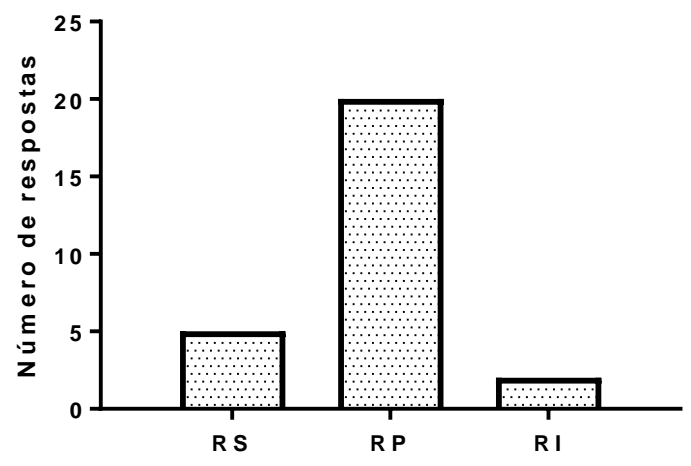

Fonte: Autores.

Todos os alunos responderam o estudo de caso, ou seja, nenhuma resposta foi classificada na categoria NR. A partir do gráfico ainda é possível inferir que cinco estudantes resolveram completamente o caso (RS) e 20 resolveram parcialmente (RP). Além disso, verifica-se que apenas dois estudantes marcaram apenas alternativas incorretas, não solucionando o caso. A seguir apresentam-se exemplos de justificativas descritas nas respostas indicadas como satisfatórias (RS), ou seja, com a indicação das opções A, B e E:

\section{Exemplo 1.}

(A) Fazer uma reconstrução a base de queratina e aminoácidos, para repor a estrutura do cabelo.

-Refazer a estrutura que foi rompida.

(B) Se Maqui fez alisamento a base de tioglicolato não poderá fazer outro a base de $\mathrm{NaOH}$.

-Vai haver reação química entre os produtos e haverá o rompimento do fio. 
(E) Uniformizar o cabelo de Maqui com tonalizante e aconselhá-la a não fazer mais alisamentos por um tempo. Indicar produtos que minimizem o frizz, e hidratações tanto compradas quanto caseiras.

-Recuperar o cabelo (estrutura física e química) para depois fazer outros procedimentos.

No caso das respostas parciais (RP) os alunos marcaram uma ou duas alternativas corretas, acompanhada ou não de justificativa. Nesta categoria verifica-se que estes compreenderam os conceitos discutidos em aula, porém acabaram não assinalando todas as alternativas corretas:

\section{Exemplo 1.}

(E) Uniformizar o cabelo de Maqui com tonalizante e aconselhá-la a não fazer mais alisamentos por um tempo. Indicar produtos que minimizem o frizz, e hidratações tanto compradas quanto caseiras.

-Como ela usou muitos produtos que danificaram as cadeias secundárias e terciárias do cabelo ela precisa reconstruir essa fibra capilar.

\section{Exemplo 2.}

(A) Fazer uma reconstrução a base de queratina e aminoácidos, para repor a estrutura do cabelo.

-Tratar o cabelo para repor as proteínas necessárias para a saúde capilar.

Os alunos que apresentaram resposta insatisfatória (RI) além de não indicarem as alternativas corretas, ainda não justificaram ou quando justificaram esta estava inadequada, conforme exemplo a seguir:

\section{Exemplo 1.}

(D) É possível uniformizar o cabelo de Maqui utilizando um tonalizante sem amônia, deixando o cabelo descolorido próximo a cor original, então poderá fazer um alisamento a base de tioglicolato, porém o mais fraco que o mercado oferecer.

- O profissional deve esclarecer as consequências, podendo utilizar o mesmo alisante anterior e uma coloração mais leve. Não sei explicar.

Esses resultados evidenciam que os alunos apresentaram dificuldade na resolução da atividade, apesar de apenas dois não resolverem o caso. Este achado pode ser decorrente da falta de experiência dos alunos em desenvolverem atividades com esta abordagem, ou ainda por não terem compreendido que poderiam assinalar várias alternativas para a resolução do caso.

Destaca-se que este trabalho vem no sentido de romper com o ensino tradicional baseado na memorização, fragmentação e simples reprodução dos conteúdos (Moreira, 2011; Moran, 2017). Assim, a adoção da resolução de casos permitiu, aos estudantes, não somente a solução de problemas, mas, também desenvolver uma postura questionadora na tentativa de identificar as soluções compatíveis para a situação proposta, ainda que nem todos os alunos tenham conseguido responder completamente o mesmo (Bittencourt \& Struchiner, 2015). Neste sentido, tal abordagem, auxiliou na aplicação dos conhecimentos discutidos em sala de aula, além de proporcionar a relação entre o procedimento estético de alisamento e a Bioquímica.

\section{Considerações Finais}

O objetivo deste trabalho foi propor e aplicar um estudo de caso por meio da temática "alisamento capilar" com estudantes de um curso de Licenciatura, visando avaliar e aprimorar os conceitos de proteínas, além de abordar esse 
conhecimento de forma inter-relacionada com o cotidiano do aluno.

Destaca-se que, conforme dados da literatura, diversos estudos têm demonstrado que essa abordagem metodológica contribui para proporcionar a aprendizagem mais profunda de conceitos. Uma vez que, exige a compreensão e aplicação dos conteúdos científicos em situações reais.

Conforme sugerido nos resultados, os alunos apresentaram dificuldade na resolução dos casos. Desta forma, evidencia-se o desafio que o desenvolvimento da $\mathrm{ABC}$ oferece aos estudantes e professores na resolução de casos atrelados a compreensão de conceitos científicos.

Espera-se com essa pesquisa colaborar com estudos sobre métodos de ensino que preveem a participação ativa do aluno no processo de ensino-aprendizagem. Como pesquisas futuras, salienta-se que a ABC pode ser explorada nas mais diversas áreas do conhecimento e níveis de ensino. Além disso, são necessários mais estudos com a abordagem utilizada nesta investigação, com vistas a compreender as dificuldades dos alunos para aprender os conceitos de proteínas.

\section{Referências}

Anvisa. RDC N ${ }^{\circ}$ 7. Ministério da Saúde. Anexo I.

Bardin, L. (1977). Análise de conteúdo. Tradução de Luís Antero Reto e Augusto Pinheiro. Edições 70.

Bittencourt, L.P. \& Struchiner, M. (2015). A articulação da temática da doação de sangue e o ensino de biologia no Ensino Médio: uma pesquisa baseada em design. Ciência \& Educação, 21(1), 159-176.

Campbell, M. (2000). Bioquímica. (3a ed.), ArtMed.

Cruz, C.F., Costa, C., Gomes, A. C., Matamá, T., \& Cavaco-Paulo, A. (2016). Human hair and the impact of cosmetic procedures: A Review on cleansing and shape-modulating cosmetics. Cosmetics, 3(3), 1-22.

Damiani, M. F., Rochefort, R. S., Castro, R. F., Dariz, M. R., Pinheiro, S. S. (2013). Discutindo pesquisas do tipo intervenção pedagógica. Cadernos de educação, (45), 57-67.

Dias, T. C. S., Baby, A. R., Kaneko, T. M. \& Velasco, M.V.R. (2007). Relaxing/straightening of Afro-ethnic hair: historical overview. Journal of Cosmetic Dermatology, 6(1), 2-5.

Ferreira, L. A., Braga, D. C. (2016). Substâncias ativas do alisamento capilar e seus mecanismos de ação. Revista Eletrônica de Farmácia, 3(2), 56-63.

Metzner, A. C. (2014). Proposta didática para o curso de licenciatura em educação física: aprendizagem baseada em casos. Educação e Pesquisa, 40(3), 637650 .

Moreira, M. A. (2011). Abandono da narrativa, ensino centrado no aluno e aprender a aprender criticamente. Ensino, Saúde e Ambiente, 4(1), 1-17.

Moran, J. M. (2017). Como transformar nossas escolas. In: Carvalho, M (Org). Educação 3.0: Novas perspectivas para o ensino. ED. UNISINOS; Porto Alegre: SINEPE RS.

Motta, V.T. (2003). Bioquímica clínica para o laboratório: princípios e interpretação. (4a ed.), Editora Médica Missau.

Nascimento, J. L. \& Feitosa, R. A. (2020). Metodologias ativas, com foco nos processos de ensino e aprendizagem. Research, Society and Development, 9(9), e622997551-e622997551.

Nelson, D. L. \& Cox, M. M. (2014). Princípios de Bioquímica de Lehninger. (6a ed.), Sarvier.

Silva, L. G. (2018). Alisamento capilar: uma temática para a abordagem de proteína. Trabalho de conclusão de curso. Ciências da Natureza - Licenciatura. Universidade Federal do Pampa.

Silva, L. D., Maia, A. F., Pazinato, M. S. \& Sudati, J. H. (2017). Percepções dos Licenciandos em Ciências da Natureza sobre Aminoácidos e Proteínas. Debates em Ensino de Química, 3 (2),142-155.

Syed, A. N. (1977). Ethnic hair care products. In: DH Johnson, ed. Hair and Hair Care, Marcel Dekker.

Tibell, L. A. E. \& Rundgren, C. J. (2010). Educational challenges of molecular life science: characteristics and implications for education and research. CBELife Sciences Education, 9(1), 25-33.

Thistlethwaite, J. E., Davies, D., Ekeocha, S., Kidd, J. M., MacDougall, C., Matthews, P., Purkis, J. \& Clay, D. (2012). The effectiveness of case-based learning in health professional education. A BEME systematic review: BEME Guide n. 23. Medical Teacher, 34(6), e421-e444.

Welter, R. B., Foletto, D. S. \& Bortoluzzi, V. I. (2020). Metodologias ativas: uma possibilidade para o multiletramento dos estudantes. Research, Society and Development. 9(1), e106911664. 
Research, Society and Development, v. 10, n. 4, e10410413892, 2021

(CC BY 4.0) | ISSN 2525-3409 | DOI: http://dx.doi.org/10.33448/rsd-v10i4.13892

Zoller, U. (1993). Are lecture and learning compatible? Maybe for LOCS: unlikely for HOCS. Journal of Chemical Education, 70(3), 195-197. 